\title{
When to Discharge a Patient After Endoscopy: A Narrative Review
}

\author{
Swapnil Sahebrao Walke, Shamshersingh Chauhan, Vikas Pandey, Rahul Jadhav, Vipul Chaudhari, Deepti Vishwanathan, Kailash \\ Kolhe, and Meghraj Ingle \\ Department of Gastroenterology, LTMMC \& LTMGH, Sion, Mumbai, India
}

Video endoscopy is an important modality for the diagnosis and treatment of various gastrointestinal diseases. Most endoscopic procedures are performed as outpatient basis, sometimes requiring sedation and deeper levels of anesthesia. Moreover, advances in endoscopic techniques have allowed invasion into the third space and the performance of technically difficult procedures that require the utmost precision. Hence, formulating strategies for the discharge of patients requiring endoscopy is clinically and legally challenging. In this review, we have discussed the various criteria and scores for the discharge of patients who have undergone endoscopic procedures with and without anesthesia. Clin Endosc 2022;55:8-14

Key Words: Advanced endoscopy; Anaesthesia; Safe discharge

\section{INTRODUCTION}

Globally, video endoscopy is used to carry out many diagnostic and therapeutic procedures related to the gastrointestinal (GI) tract. Advanced endoscopic procedures, such as endoscopic retrograde cholangiopancreatography (ERCP), endoscopic ultrasound (EUS), third-space endoscopic procedures, and endoscopy performed for GI bleeding may require the help of an anesthesiologist for sedation, even at the time of endotracheal intubation.

The time of discharge after endoscopy will depend on the type of procedure and anesthesia administered, complications during and after the procedure, and any underlying clinical conditions of the patient. Some patients can undergo diagnostic and therapeutic endoscopies without sedation, but

\footnotetext{
Received: March 22, 2021 Revised: May 8, 2021

Accepted: June 8, 2021

Correspondence: Meghraj Ingle

Department of gastroenterology, LTMMC \& LTMGH, Endoscopy room 13, College building, First Floor, Sion, Mumbai 400022, India

Tel: +91-93209-79659, Fax: +91-022-240-63000, E-mail: drmeghraj@gmail.com ORCID: https://orcid.org/0000-0001-9042-3047
}

(cc) This is an Open Access article distributed under the terms of the Creative Commons Attribution Non-Commercial License (http://creativecommons.org/ licenses/by-nc/3.0) which permits unrestricted non-commercial use, distribution, and reproduction in any medium, provided the original work is properly cited. most patients and endoscopists prefer sedation or anesthesia for advanced endoscopic procedures. ${ }^{1}$ Therefore, we tried to highlight the appropriate timing and criteria based on current evidence of discharge after endoscopic procedures with or without sedation.

\section{POST-ANESTHESIA DISCHARGE SCORES}

Few scores have been defined in the literature that help in decision-making for safe patient discharge after the effects of anesthesia subside. The Aldrete scoring system (Table 1) and modified post-anesthesia discharge scoring system (PADSS, Table 2) help the treating physician determine when to discharge a patient post-procedure. ${ }^{1}$ However, these have yet to be prospectively validated.

The Aldrete scoring system includes five parameters: oxygen saturation, blood pressure, respiration, consciousness, and activity. A score $\geq 9$ may indicate discontinuation of monitoring, and the patient can be discharged. ${ }^{2}$

The modified PADSS incorporates systolic blood pressure, postoperative nausea/vomiting, activity, pain, and surgical bleeding. ${ }^{2}$ If the post-procedure score is $>9$ or vital sign score is $>2$ and other sub scores are $>1$, the patient can be discharged after 6 hours. ${ }^{2}$ Trevisani et al. studied this score in 
patients undergoing sedation with meperidine and midazolam during colonoscopy. Patients with a modified PADSS score $>9$ could be discharged within 2 hours. ${ }^{3}$ However, prospective studies are required to recommend the timing of starting oral feeds after discharge.

A recent paper by Sato et al. recently highlighted the safe use of propofol for diagnostic and therapeutic esophagogastroduodenoscopy and colonoscopy. The patient was discharged when there was full recovery of psychomotor functions and consciousness, which were evaluated using a pragmatic approach. Answering the questions asked by the recovery nurse and the ability to walk in a straight line for at least five meters, assessed 1 hour after the procedure by a recovery nurse, prompted immediate discharge from the endoscopy unit. ${ }^{4}$ Aljebreen stud- ied the average time to discharge after sedated and unsedated colonoscopies and showed that recovery was significantly faster in patients who were unsedated than in those who were sedated. ${ }^{5}$

The American Society of Anesthesiologists defines moderate sedation (conscious sedation) as a drug-induced depression of consciousness during which patients respond purposefully to verbal commands, either alone or accompanied by light tactile stimulation, with interventions being required to maintain the patent's airway, and spontaneous ventilation is adequate. ${ }^{6}$ Using this definition, Lugay and colleagues showed that the mean recovery time after an endoscopic procedure was $<50 \mathrm{~min}^{6}$

Table 1. Aldrete Scoring System

\begin{tabular}{|c|c|}
\hline Categories & Score \\
\hline \multicolumn{2}{|l|}{ Respiration } \\
\hline Able to take deep breath \& cough & 2 \\
\hline Dyspnea and shallow breathing & 1 \\
\hline Apnea & 0 \\
\hline \multicolumn{2}{|l|}{ Oxygen saturation } \\
\hline $\mathrm{SaO} 2>95 \%$ on room air & 2 \\
\hline Dyspnea and shallow breathing & 1 \\
\hline Apnea & 0 \\
\hline \multicolumn{2}{|l|}{ Consciousness } \\
\hline Fully awake & 2 \\
\hline Arousable on call & 1 \\
\hline Not responding & 0 \\
\hline \multicolumn{2}{|l|}{ Circulation } \\
\hline Blood pressure $+/-20 \mathrm{mmHg}$ baseline & 2 \\
\hline Blood pressure $+/-20-50 \mathrm{mmHg}$ baseline & 1 \\
\hline Blood pressure $+/-50 \mathrm{mmHg}$ baseline & 0 \\
\hline \multicolumn{2}{|l|}{ Activity } \\
\hline Able to move 4 extremities & 2 \\
\hline Able to move 2 extremities & 1 \\
\hline Able to move 0 extremities & 0 \\
\hline
\end{tabular}

Monitoring may be discontinued and patient discharged to home or appropriate unit when Aldrete score more than 9 or return to baseline Aldrete score. 
Table 2. Modified Post Anaesthesia Discharge Scoring System

\begin{tabular}{|c|c|}
\hline Categories & Score \\
\hline \multicolumn{2}{|l|}{ Vital signs (blood pressure, pulse, heart rate ) } \\
\hline $\pm 40 \%$ of pre-endoscopy value & 0 \\
\hline $\pm 20-40 \%$ of pre-endoscopy value & 1 \\
\hline $\pm 20 \%$ of pre-endoscopy value & 2 \\
\hline \multicolumn{2}{|l|}{ Activity } \\
\hline Unable to ambulate & 0 \\
\hline Requires assistance & 1 \\
\hline Steady gait, no dizziness or meets pre-endoscopy level & 2 \\
\hline \multicolumn{2}{|l|}{ Nausea and vomiting } \\
\hline Severe/continues despite treatment & 0 \\
\hline Moderate/treated with parenteral medication & 1 \\
\hline No or minimal/treated with p.o. medication & 2 \\
\hline \multicolumn{2}{|l|}{ Pain } \\
\hline Severe (numerical analogue scale $=7-10$ ) & 0 \\
\hline Moderate (numerical analogue scale $=4-6$ ) & 1 \\
\hline Minimal or no pain (numerical analogue scale $=0-3$ ) & 2 \\
\hline \multicolumn{2}{|l|}{ Surgical bleeding } \\
\hline Severe ( $\geq 2$ episodes of hematemesis or rectal bleeding) & 0 \\
\hline Moderate (1 episode of hematemesis or rectal bleeding) & 1 \\
\hline None or minimal (not requiring intervention) & 2 \\
\hline
\end{tabular}

Patients' scoring $\geq 9$ for two consecutive measurements are considered fit for discharge home.

p.o, per os.

\section{NONVARICEAL BLEEDING}

Patients with nonvariceal upper GI bleeding can be stratified based on the complete Rockall score and Glasgow Blatchford score (GBS). Patients can be discharged early if the Rockall score ranges from 0 to $2 .^{7}$ A study by Le Jeune et al. suggested that patients with GBS $<2$ could be considered for early discharge, ${ }^{1}$ which was also validated in a study conducted by Rickard et al. ${ }^{8}$

The presence of endoscopic stigmata of recent bleeding also determines the risk of rebleeding and may predict the length of hospital stay for affected patients. High-risk stigmata include active arterial bleeding, a non-bleeding visible vessel, or an adherent clot. The patients in whom these occur need endoscopic haemostatic measures and intravenous infusions of proton pump inhibitors (PPIs) in the hospital for about three days. ${ }^{9}$

Intermediate-risk stigmata include oozing from an ulcer and no other endoscopic stigmata, severe comorbidities, or shock on presentation. The patients in whom these occur should undergo endoscopic management followed by oral PPIs and observation in the hospital for 1-2 days after successful endoscopic treatment.'

Low-risk stigmata include clean-based ulcers or flat spots on the ulcer base. These patients should be started on oral PPIs once a day, can resume a normal diet immediately, and be discharged from the emergency department or hospital when stable. ${ }^{10}$ Patients with hemoglobin levels $>10 \mathrm{mg} / \mathrm{dL}$, normal coagulation parameters, and good social support at home can be discharged immediately after the procedure.

\section{VARICEAL BLEEDING}

For cirrhotic patients presenting with variceal bleeding, upper GI endoscopy should be performed as soon as possible after hemodynamic stability or within 12 hours of admission. ${ }^{11}$

Once variceal bleeding is confirmed, vasoactive drugs need to be avoided for five days to avoid rebleeding. A shorter administration duration of vasoactive drugs (48-72 hours) can 
be considered in cases with less severe GI bleeding, but more data are needed. ${ }^{11,12}$ In compensated cirrhotic patients undergoing variceal banding as primary or secondary prophylaxis for esophageal varices, endoscopic therapy can be administered on an outpatient basis without requiring admission. However, patients requiring endoscopic therapy for gastric varices by cyanoacrylate injection may require extended observation if any intraprocedural bleeding occurs. Patients can be discharged after successful endoscopic variceal bleeding control and vasoactive drug therapy if their hospital course remains uncomplicated. ${ }^{11,12,13}$

\section{LUMINAL DILATATION AND STENTING}

Guidelines are available for monitoring and discharge post-esophageal dilatation. Patients were monitored for at least two hours before discharge. Patients should be provided with clear oral and written instructions on fluids, diet, and medications. Routine imaging and contrast studies post-procedure should be performed only in cases of post-procedure persistent chest pain, fever, tachycardia, or breathlessness. ${ }^{14}$

There are no data regarding discharge after uncomplicated pneumatic dilatation for achalasia and balloon dilatation for enteric and colonic pathologies. Different hospitals follow their own discharge policies, ranging from a few hours to almost a day. At our institution, we generally observe the patient for about 4 hours post-dilatation for any evidence of severe or persistent chest pain, persistent tachycardia, or breathlessness. In patients who underwent pyloric, enteral, or colonic balloon dilatation, we observe these patients for approximately 2 hours post-procedure and discharged these patients if the procedure was uncomplicated.

Patients undergoing enteral stenting may be monitored for a few hours prior to discharge. One study from India followed a protocol to discharge the patients on postoperative day 3 after they tolerated oral feeds. ${ }^{15}$ However, if stenting is performed for perforation, the patient may have an extended hospital stay. At our institution, if esophageal stenting is performed for palliation of dysphagia due to cancer or stent placement for a benign stricture, the patient is discharged after 4 hours of observation if the procedure is uneventful. Patients undergoing antral stenting for palliation of malignant gastric outlet obstruction can be discharged 1-2 days later, provided they have immediate access to medical facilities. ${ }^{16}$ Patients undergoing colonic stenting for malignant obstruction may be discharged after a median of six days post-procedure, as shown in a study by Ho et al. ${ }^{17}$

\section{FOREIGN BODY REMOVAL}

Aspiration, perforation, and GI bleeding are life-threatening complications associated with foreign body ingestion. Endoscopic management of most patients who ingested foreign bodies or had an impacted food bolus can be treated on an outpatient basis. ${ }^{18}$ Patients with a technically demanding extraction; who ingested multiple objects or foreign bodies, which is associated with a high risk for complications (i.e., sharp-pointed objects, batteries, magnets, objects larger than 5-6 cm); or who have extensive mucosal injury due to foreign body ingestion or endoscopic treatment require admission and observation. ${ }^{18}$ However, the length of stay is not defined. We suggest admission and observation of the patient for 24 hours post-procedure and discharge if no complication occurs.

\section{PERCUTANEOUS ENDOSCOPIC GASTROSTOMY}

Patients undergoing percutaneous endoscopic gastrostomy (PEG) have underlying medical or surgical comorbidities that require hospital admission before the PEG procedure. An important consideration after PEG insertion is the initiation of feeding. A meta-analysis by Bechtold et al. showed that early feeding (defined as $<4$ hours) may be a safe alternative to delayed ( $>4$ hours) or next-day feeding. Despite the significant increase in gastric residual volumes at day 1 , no increase in overall complications was seen. ${ }^{19} \mathrm{~A}$ study by Gumaste et al. on early ( $<3$ days) vs. late discharge post-PEG showed that serum albumin level $<2.2 \mathrm{~g} / \mathrm{dL}$, age, and two or more comorbidities were independent predictors of late discharge from the hospital. $^{18}$

\section{ENDOSCOPIC MUCOSAL RESECTION AND ENDOSCOPIC SUBMUCOSAL DISSECTION}

Endoscopic mucosal resection (EMR) and endoscopic submucosal dissection (ESD) may be associated with adverse events, such as perforation and bleeding. These complications are major reasons for extended hospital stays. For ESD, recent data show an average of 5-8 days of hospitalization. ${ }^{20}$ Choi et al. analyzed EMR and ESD data and found that delayed complications were rarely observed when the patient was discharged within two days after the procedure. ${ }^{21}$ Tomiki proposed and validated a post-colonic ESD 3-day discharge algorithm. ${ }^{22}$ Patients with intraoperative perforation or bleeding 
fasted until day 2 and were later managed according to their symptoms. Other patients fasted only for day 1 , and those with normal physical, imaging, and laboratory parameters (white blood cell count $<10,000 / \mu \mathrm{L}, \mathrm{C}$-reactive protein $<2 \mathrm{mg} / \mathrm{L}$ ) were discharged on day $3 .^{22}$

\section{PERORAL ENDOSCOPIC MYOTOMY}

Among the few proposed benefits of peroral endoscopic myotomy (POEM) over surgery is the reduced length of hospital stay.

Pioneer work by Inoue et al., which included 500 patients, described the average duration of hospital stay after POEM to be $4-5$ days. ${ }^{23}$ In a prospective study by Cloutier, the discharge criteria for POEM included the ability to tolerate oral fluids and good pain control on regular acetaminophen intake. In this study, 72 (79.1\%) patients who underwent POEM were discharged on the same day. ${ }^{24}$

\section{ERCP}

ERCP can be performed on an outpatient basis. Complications such as post-ERCP pancreatitis (PEP), bleeding, perfo- ration, and cholangitis may extend the duration of stay after ERCP. Many studies have been conducted on early discharge after ERCP and factors predicting complications of ERCP, such as PEP. Jeurnink proposed a predictor model for PEP and cholangitis. ${ }^{25}$ This score includes pre-cut sphincterotomy, age $<60$ years, primary sclerosing cholangitis, female sex, history of pancreatitis, pancreas divisum, and difficult cannulation (1 point for each parameter). Patients with a score $<3$ can be discharged after 6 hours of observation, and those with a score $>4$ may need admission and observation. Lee et al. studied 4 hour amylase and lipase levels after ERCP for predicting PEP. $^{26}$ An amylase level $<1.5 \times$ upper limits of normal (ULN) was useful for PEP exclusion (sensitivity of $93.8 \%$ ), and $>4 \times$ ULN was more specific (93.2\%) and useful to guide preventive therapy. Lipase levels $>2 \times$ ULN and $>8 \times$ ULN had high sensitivity and specificity, respectively.

A 4 -hour post-ERCP amylase level $>4 \times$ ULN, lipase level $>8 \times$ ULN, pre-cut sphincterotomy, and pancreatic sphincterotomy were significant predictors for PEP. Therefore, patients with an amylase level $<1.5 \times$ ULN and a lipase level $<4 \times$ ULN may be considered for safe early discharge. ${ }^{26}$ Freeman determined certain risk factors that would warrant longer hospital stays post-ERCP. Suspected sphincter of Oddi dysfunction, cirrhosis, difficult bile duct cannulation, and combined endoscopic and percutaneous procedures are risk

Table 3. Proposed Discharge Criteria for Various Endoscopic Procedures

\begin{tabular}{|c|c|c|}
\hline Procedure & Criteria for discharge & Discharge \\
\hline If anesthesia given & $\begin{array}{c}\text { Modified Aldrete score }^{2}>9 \\
\text { PADSS }^{3}>9\end{array}$ & Same day (6-hour observation) \\
\hline Post non-variceal upper GI bleeding & $\begin{array}{l}\text { Glasgow Blatchford score } e^{1,9,10} \\
\qquad 2 \\
>2\end{array}$ & $\begin{array}{c}\text { Same day discharge } \\
\text { Admission and stabilization }\end{array}$ \\
\hline Esophageal dilatation-uncomplicated & At least 2-hour observation ${ }^{14}$ & Same day in uncomplicated cases \\
\hline Foreign body removal & $\begin{array}{l}\text { Uncomplicated }^{18} \\
\text { Complicated }^{17}\end{array}$ & $\begin{array}{c}\text { Immediately post removal } \\
\text { Observation for at least } 24 \text { hours }\end{array}$ \\
\hline POEM-uncomplicated & Observation for 1 day $^{20}$ & Observation for 1 day \\
\hline EMR and ESD-uncomplicated & 2 days ${ }^{22}$ & 2 days \\
\hline $\begin{array}{l}\text { ERCP-prognostic model score for pancreatitis and } \\
\text { cholangitis }\end{array}$ & $\begin{array}{l}0-3^{26} \\
>4^{26}\end{array}$ & $\begin{array}{l}\text { Same day discharge after six hours } \\
\text { Keep for observation for } 24 \text { hours }\end{array}$ \\
\hline EUS uncomplicated pancreatic fluid drainage & $2-3$ days $^{29,30}$ & $2-3$ days \\
\hline ERCP-biliary malignancy & Same day discharge $e^{28}$ & Same day discharge \\
\hline
\end{tabular}

EMR, endoscopic mucosal resection; ERCP, endoscopic retrograde cholangiopancreatography; ESD, endoscopic submucosal dissection; EUS, endoscopic ultrasound; GI, gastrointestinal; POEM, peroral endoscopic myotomy 
factors for post-ERCP complications, and the presence of any one of these factors merits observation for 6 hours to prevent readmission. ${ }^{27}$ Therefore, same-day discharge is safe even after uneventful ERCP, regardless of whether stenting is performed for choledocholithiasis or biliary malignancy. ${ }^{28}$

\section{ENDOSCOPIC ULTRASOUND-ASSISTED INTERVENTIONAL PROCEDURES}

Studies comparing EUS and surgical approaches for pseudocyst drainage show similar efficacy, but the EUS approach may reduce the duration of hospital stays and costs of the procedure, and improve quality of life..$^{29-31}$ Various studies noted hospital stays ranging from 2 to 4 days post-procedure, which is less than that for surgical drainage (6-10 days). Mok et al. established the safety of therapeutic endoscopy (ERCP and endoscopic ultrasound-guided fine needle aspiration [EUS-FNA]) in an ambulatory surgery center as the incidence of adverse events was equivalent to that among inpatients. ${ }^{32}$ In this prospective study, which includes $>270$ patients who had undergone procedures such as ERCP and EUS-FNA, more than half of the patients were very sick at the time of endoscopy (American Society of Anesthesiologists grade III and above). However, the overall ERCP- and EUS-FNA-related adverse events, including pancreatitis and hemorrhage, were not different between inpatients and patients undergoing ambulatory endoscopies.

Well-documented verbal and written instructions outlining diet, activity, medication, and follow-up evaluation should be given to each patient after every procedure, preferably in their native language. A concerned contact person and 24-hour helpline should be provided to all patients in case of a complication related to the endoscopic procedure. On discharge, a responsible individual should accompany the patients home.

\section{CONCLUSIONS}

Many endoscopic procedures do not have well-defined discharge criteria. Therefore, the decision to discharge needs to be considered on a case-by-case basis. In Table 3, the authors suggest various GI procedures with their need for admission and possible length of stay based on current evidence; however, there are no definite guidelines. Thus, prospective studies evaluating this simple yet important topic would help further illuminate this common problem.
Conflicts of Interest

The authors have no potential conflicts of interest.

Funding

None.

Author Contributions

Conceptualization: Swapnil Walke, Meghraj Ingle, Vikas Pandey

Formal analysis: SW, Shamshersingh Chauhan, Rahul Jadhav, Vipul Chaudhari, Deepti Vishwanathan

Project administration: SW

Writing-original draft: SW, SC, RJ, VP

Writing-review\&editing: SW, MI, SC

ORCID

Swapnil Walke

Shamshersingh Chauhan

Vikas Pandey

Rahul Jadhav

Vipul Chaudhari

Deepti Vishwanathan

Kailash Kolhe

Meghraj Ingle

https://orcid.org/0000-0001-7367-176X https://orcid.org/0000-0003-1035-8922 https://orcid.org/0000-0001-5184-8149 https://orcid.org/0000-0002-6598-1706 https://orcid.org/0000-0001-8610-8896 https://orcid.org/0000-0002-8107-8023 https://orcid.org/0000-0003-3520-8277 https://orcid.org/0000-0001-9042-3047

\section{REFERENCES}

1. Cohen LB, Delegge MH, Aisenberg J, et al. AGA Institute review of endoscopic sedation. Gastroenterology 2007;133:675-701.

2. Dumonceau J-M, Riphaus A, Schreiber F, et al. Non-anesthesiologist administration of propofol for gastrointestinal endoscopy: European Society of Gastrointestinal Endoscopy, European Society of Gastroenterology and Endoscopy Nurses and associates guideline-updated June 2015. Endoscopy 2015;47:1175-1189.

3. Trevisani L, Cifalà V, Gilli G, Matarese V, Zelante A, Sartori S. Post-anaesthetic discharge scoring system to assess patient recovery and discharge after colonoscopy. World J Gastrointest Endosc 2013;5:502-507.

4. Sato M, Horiuchi A, Tamaki M, et al. Safety and effectiveness of nurse-administered propofol sedation in outpatients undergoing gastrointestinal endoscopy. Clin Gastroenterol Hepatol 2019;17:1098-1104.e1.

5. Aljebreen AM, Almadi MA, Leung FW. Sedated vs unsedated colonoscopy: a prospective study. World J Gastroenterol 2014;20:5113-5118.

6. Practice guidelines for moderate procedural sedation and analgesia 2018: a report by the American Society of Anesthesiologists task force on moderate procedural sedation and analgesia, the American Association of Oral and Maxillofacial Surgeons, American College of Radiology, American Dental Association, American Society of Dentist Anesthesiologists, and Society of Interventional Radiology. Anesthesiology 2018;128:437-479.

7. Lugay M, Otto G, Kong M, Mason DJ, Wilets I. Recovery time and safe discharge of endoscopy patients after conscious sedation. Gastroenterol Nurs 1996;19:194-200.

8. Rockall TA, Logan RF, Devlin HB, Northfield TC. Selection of patients for early discharge or outpatient care after acute upper gastrointestinal haemorrhage. National Audit of Acute Upper Gastrointestinal Haemorrhage. Lancet 1996;347:1138-1140.

9. Rickard A, Squire R, Freshwater DA, Smith JE. Validation of the Glasgow Blatchford score to enable safe discharge of selected patients with upper GI bleeding. J R Nav Med Serv 2012;98:12-14.

10. Jensen DM, Eklund S, Persson T, et al. Reassessment of rebleeding risk of Forrest IB (oozing) peptic ulcer bleeding in a large international randomized trial. Am J Gastroenterol 2017;112:441-446. 
11. Longstreth GF, Feitelberg SP. Outpatient care of selected patients with acute non-variceal upper gastrointestinal haemorrhage. Lancet 1995;345:108-111.

12. de Franchis R, Baveno VI Faculty. Expanding consensus in portal hypertension: report of the Baveno VI consensus workshop: stratifying risk and individualizing care for portal hypertension. J Hepatol 2015;63:743752.

13. Garcia-Tsao G, Sanyal AJ, Grace ND, Carey W, Practice Guidelines Committee of the American Association for the Study of Liver Diseases, Practice Parameters Committee of the American College of Gastroenterology. Prevention and management of gastroesophageal varices and variceal hemorrhage in cirrhosis. Hepatology 2007;46:922-938.

14. Sami SS, Haboubi HN, Ang Y, et al. UK guidelines on oesophageal dilatation in clinical practice. Gut 2018;67:1000-1023.

15. Singh P, Singh A, Singh A, Sharma G, Bhatia PK, Grover AS. Long term outcome in patients with esophageal stenting for cancer esophagus our experience at a rural hospital of punjab, India. J Clin Diagn Res 2016;10:PC06-PC09.

16. Martin DF, Laasch H-U. Gastroduodenal stenting. Semin Intervent Radiol 2004:21:167-179.

17. Ho K-S, Quah H-M, Lim J-F, Tang C-L, Eu K-W. Endoscopic stenting and elective surgery versus emergency surgery for left-sided malignant colonic obstruction: a prospective randomized trial. Int J Colorectal Dis 2012;27:355-362.

18. Birk M, Bauerfeind P, Deprez PH, et al. Removal of foreign bodies in the upper gastrointestinal tract in adults: European Society of Gastrointestinal Endoscopy (ESGE) clinical guideline. Endoscopy 2016;48:489-496.

19. Bechtold ML, Matteson ML, Choudhary A, Puli SR, Jiang PP, Roy PK. Early versus delayed feeding after placement of a percutaneous endoscopic gastrostomy: a meta-analysis. Am J Gastroenterol 2008;103:29192924.

20. Gumaste VV, Bhamidimarri KR, Bansal R, Sidhu L, Baum J, Walfish A. Factors predicting early discharge and mortality in post-percutaneous endoscopic gastrostomy patients. Ann Gastroenterol 2014;27:42-47.

21. Kim Y, Kim YW, Choi IJ, et al. Cost comparison between surgical treatments and endoscopic submucosal dissection in patients with early gastric cancer in Korea. Gut Liver 2015;9:174-180.
22. Choi JY, Park YS, Na G, et al. Safety and effectiveness of endoscopic mucosal resection or endoscopic submucosal dissection for gastric neoplasia within 2 days' hospital stay. Medicine (Baltimore) 2019;98:e16578.

23. Tomiki Y, Kawai M, Takehara K, et al. Clinical pathway to discharge 3 days after colorectal endoscopic submucosal dissection. Dig Endosc 2015;27:679-686.

24. Inoue $\mathrm{H}$, Sato H, Ikeda H, et al. Per-oral endoscopic myotomy: a series of 500 patients. J Am Coll Surg 2015;221:256-264.

25. Cloutier Z, Mann A, Doumouras AG, Hong D. Same-day discharge is safe and feasible following POEM surgery for esophageal motility disorders. Surg Endosc 2021;35:3398-3404.

26. Jeurnink SM, Siersema PD, Steyerberg EW, et al. Predictors of complications after endoscopic retrograde cholangiopancreatography: a prognostic model for early discharge. Surg Endosc 2011;25:2892-2900.

27. Lee YK, Yang MJ, Kim SS, et al. Prediction of post-endoscopic retrograde cholangiopancreatography pancreatitis using 4 -hour post-endoscopic retrograde cholangiopancreatography serum amylase and lipase levels. J Korean Med Sci 2017;32:1814-1819.

28. Freeman ML, Nelson DB, Sherman S, et al. Same-day discharge after endoscopic biliary sphincterotomy: observations from a prospective multicenter complication study. The Multicenter Endoscopic Sphincterotomy (MESH) Study Group. Gastrointest Endosc 1999;49:580-586.

29. Varadarajulu S, Bang JY, Sutton BS, Trevino JM, Christein JD, Wilcox $\mathrm{CM}$. Equal efficacy of endoscopic and surgical cystogastrostomy for pancreatic pseudocyst drainage in a randomized trial. Gastroenterology 2013;145:583-590.e1.

30. Varadarajulu S, Lopes TL, Wilcox CM, Drelichman ER, Kilgore ML, Christein JD. EUS versus surgical cyst-gastrostomy for management of pancreatic pseudocysts. Gastrointest Endosc 2008;68:649-655.

31. Melman L, Azar R, Beddow K, et al. Primary and overall success rates for clinical outcomes after laparoscopic, endoscopic, and open pancreatic cystgastrostomy for pancreatic pseudocysts. Surg Endosc 2009;23:267271.

32. Mok SRS, Ho HC, Gaughan JP, Elfant AB. Therapeutic endoscopy can be performed safely in an ambulatory surgical center: a multicenter, prospective study. Diagn Ther Endosc 2016;2016:7168280. 